This paper was inadvertently omitted from the Proceedings of the Colloquium "Status of Transplant Technology in the United States, Orient, and Australia: New Ideas from Research for Commercial Adaptation," published in HortTechnology 3(4):405-420. Reprints of the Colloquium in its entirety are available from ASHS Headquarters.

\section{Long-term Consequences and Significance of Short-term Pretransplant Nutritional Conditioning}

\section{Robert J. Dufault'}

Additional Index words. transplant, hardening, stress tolerance, transplant shock, fertility

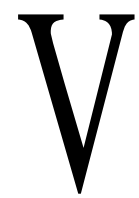

egetable transplants are being used more frequently for crops that traditionally have been direct-seeded. The reasons for the shift to transplanting have been outlined (Dufault, 1993). Quality and growth of commercially grown transplants sometimes differs from year to year. Seedlings may be robust, stocky, and vigorous in one year and spindly, chlorotic, and elongated in other years. These differences may be caused by different methods of hardening.

\section{Hardening}

The process of "hardening" has been defined as "any treatment that restricts growth (Lorenz and Maynard, 1988). The goal of hardening is to increase field survival and ensure optimal plant populations. Hardening may include one or all of the following techniques: Reduction of watering frequency, reduction or elimination of nutrients, exposure to cool temperatures, shading or exposure to high light, mechanical stress such as brushing, etc

Hardening traditionally is used to toughen

Clemson University Coastal Research and Education Center, 286.5 Savannah Highway, Charleston, SC 29414

${ }^{1}$ Associate Professor. the plant to withstand the stresses of transplanting and to reduce transplant shock. Transplant shock is induced by biotic (insects and disease) and climatic stresses (soil fertility, salts, temperatures and structure, water availability, fluctuations and extremes in air temperatures, and wind). Signs of transplant shock may include loss of leaves, yelIowing of foliage, excessive wilting; subsequently, these aberrations may reduce earliness and/or uniform maturity. Severe transplant shock may reduce plant population and lessen economic potential significantly.

Many of the commercial transplant producers use nutrient withdrawal as the major method to slow, retard, and limit transplant growth until shipping can occur (B. Thomas, Speedling, Inc., Sun City, Fla., personal communication). Nutrient-hardened and nitrogen-deficient transplants may be slower to resume rapid growth after transplanting even when sufficient $\mathrm{N}$ is applied after transplanting (Aloni et al., 1991). At transplanting, there is high sink demand for a continuous supply of assimilates, either from newly fixed $\mathrm{CO}_{z}$ or from storage pools that both may have become limited underlow-N conditions of nutrient hardening (Aloni et al., 1991), Production and mobilization of carbohydrates may be retarded in the field due to the $\mathrm{N}$-deficient status leading to slower establishment.

Hardening methods are not without disadvantages. As early as the 1940 s, it was recognized that "any hardening method used, which results in stunting or hardening young plants, permanently slows up their field performance, probably decreasing the yield roughly in proportion to the severity of the hardening treatment" (Brasher, 1941). As I stated (Dufault, 1993), earlier yields are the major advantage for using transplants. Excessive hardening, consequently, may delay production later into the season, missing early "market windows" and possibly higher income for early production. Cultural practices that reduce crop value need to be modified immediately to ensure highest value to the grower.

\section{Early seedling nutrition work}

Earlier seedling nutrition workers recognized that hardening by nutrient withdrawal can limit earliness in several vegetable crops. Hardening young tomato plants, even to a moderate degree, stunted the seedlings and diminished early yields (Brasher and Westover, 1937). Unhardened tomato, cabbage, and cauliflower seedlings were not inferior to hardened plants in their ability to withstand field conditions (Babb, 1940). Jaworski and Webb (1966) reported that conditioning field- grown tomato transplants with high $\mathrm{N}$ and low $\mathrm{P}$ reduced yield. A deficiency in $\mathrm{N}$ reduced bell pepper earliness, and excessive $\mathrm{N}$ delayed yield and gave lower total productivity (Knavel, 1977). Conditioning lettuce seedlings with a complete fertilizer increased head weight and deficits and excesses during transplant production reduced field productivity (Kratky, 1981). These observations have acted as a prelude to the concept of pretransplant nutritional conditioning (PNC).

\section{Pretransplant nutritional condition- ing research}

PNC is defined as the process of nutritionally conditioning seedlings during the greenhouse production phase to predispose the seedlings to tolerate transplant stresses better, recover quickly from transplant shock, and enhance earlier yields (Dufault, 1986). The goal of traditional fertility regimes for seedling production is to produce transplants on a prescribed schedule that will survive shipment and the transplanting ordeal. During the greenhouse production phase, the rate of seedling growth is controlled by fertility manipulation. PNC fertility regimes are chosen primarily for their long-term effect on earliness.

Since 1987, evidence has accumulated to prove PNC'S value in improving early yield of tomatoes. Weston and Zandstra (1989), in Michigan, reported earlier yield of 'Pik-Red' fresh-market tomatoes with $400 \mathrm{ppm} \mathrm{N} \mathrm{PNC} \mathrm{rate} \mathrm{than} \mathrm{with}$ 100 ppm N. 'Springset' tomato conditioned with N PNC and planted in Quebec and Montreal, Canada, yielded earlier in both locations as $\mathrm{N}$ increased to 400 ppm (Masson et al., 1991). In both of these studies, total yields were unaffected by PNC. In South Carolina, earliness of fresh-market 'Sunny' tomato increased with 200 vs. $100 \mathrm{ppm} \mathrm{N}$, and only $100 \mathrm{ppm} \mathrm{N}$ increased total yields, with no further effect with $200 \mathrm{ppm} \mathrm{N}$ (Melton and Dufault, 1991).

Conditioning seedlings with low PNC before field planting is more beneficial than hardening with total nutrient withdrawal, Garton in Canada and Widders in Michigan (1990) reported yield reductions after withdrawing nutrients 10 days prior to transplanting 'Heinz 2652 processing tomatoes. They also reported similar yields (onceover harvest) for tomatoes conditioned at low or high NPK PNC.

PNC has been attempted on several vegetable genera, with mostly positive results. Head weight of 'Florida 683 celery increased after conditioning with 400 ppm N, but 600 ppm N was considered excessive (Tremblay et al,, 1987). In follow-up work, Masson et al. (1991) reported that 
celery head weight increased linearly with $\mathrm{N}$ rate, but $300 \mathrm{ppm}$ was sufficient for maximal response. In "once-over" harvests in Quebec and Montreal, 'Emperor' broccoli yielded the largest heads with $200 \mathrm{ppm}$ N, regardless of location (Masson et al,, 1991 ). The density of lettuce heads increased $16 \%$ after conditioning seedlings with 400 vs. 100 ppm N (Masson et al., 1991).

Muskmelons traditionally are direct-seeded; however, with the high cost of hybrid seed and the desire for earliness, transplanting has become popular commercially. In Texas, I (Dufault ,1986) reported that seedlings conditioned with $250 \mathrm{~N}-$ $25 \mathrm{P}-250 \mathrm{~K}$ produced $>50 \%$ of all marketable fruit that matured in the first three of a total of 18 harvests. Fruit of seedlings conditioned with moderate to low PNC matured in mid-season, with $>50 \%$ of the production occurring from the 12th to 18th harvests. Commercially, plants conditioned with low PNC would require harvest labor much longer to realize full crop potential. The higher laborcost and lower lateseason prices may reduce the economic profitability significantly compared to the concentrated harvests reported for plants conditioned with high PNC, Although earliness was enhanced with high NPK PNC, total yield was similar with all PNC treatments.

\section{Conclusions}

The above recounts many benefits of PNC for a variety of crops, but there are many problems that need to be rectified before PNC can be used commercially. It is obvious that different vegetable crops require different nutrient regimes to prepare them for maximal performance. Even varieties within a species may behave differently, Therefore, the concept of "prescription feeding" maybe included with PNC and is conditioning particular crop varieties with unique fertility regimes, Mounting evidence suggesting varietal differences in response to PNC make it difficult to pinpoint the "best" regime for all varieties in anyone location. Additionally, prescription feeding maybe possible in operations using subsurface or ebb-and-flow irrigation systems, but impossible in other operations with simplistic plumbing systems.
Delayed shipment of "finished" PNC transplants presents postharvest handling problems. Transplants grown using PNC usually are rapidly growing and withdrawal of nutrients because of shipment delays may negate the conditioning effect. Further research is needed to find novel techniques for postharvest handling of conditioned transplants that will not annul PNC.

The questions raised in this discussion can provide direction for further seedling nutrition work. University trials have shown often that short-term nutritional conditioning does have a long-term effect, mostly on earliness, The literature shows that complete withdrawal of nutrients is detrimental and that, in general, fertilization, even at low rates, should continue to shipment.

\section{Literature Cited}

Aloni B., T. Pashkar and L. Karni. 1991.Nitrogen supply influences carbohydrate partitioning of pepper seedlings and transplant development. J. Amer. Soc. Hort, Sci. 116:995-999.

Babb, M.F. 1940. Residual effects of forcing and hardening of tomato, cabbage, and cauliflower plants. USDA Tech, Bul. 760,

Brasher, EP. 1941. Growth and yield of the tomato plant when hardening with certain nutrient solutions. Proc. Amer. Soc. Hort. Sci, 38:629-632.

Brasher, EP, and K C. Westover, 1937. The effect on yield of harden ingthetomato plant. Proc. Amer. Soct. Hort. Sci. 35:686-689.

Dufau/t, R.J. 1985. Relationship among nitrogen, phosphorus and potassium fertility regimes on celery transplant growth. HortScience 20:11041106.

Dufault R.J., 1986. Influence of nutritional conditioning on muskmelon transplant quality and early yield. J. Amer. Soc. Hort, Sci, 111:698-703.

DuFau/t, RJ. 1993, Introduction and perspective of the colloquium. "Status of transplant technology in the United States, Orient, and Australia: New ideas from research for commercial adaptation. HortTechnology 3:406.

Garton, $R$ W and/.E. Widders. 1990. Nitrogen and phosphorus preconditioning of small-plug seedlings influence processing tomato productivity. HortScience 25:655-657.

Jaworksi, CA. and R.E Webb. 1966. Influence of nutrition, clipping storage of tomato transplants on survival and yield. Proc. Fla. State Hort. Soc. 79:216-221,

Knave/, D.E. 1977 The influences of nitrogen on pepper transplant growth and yielding potential of plants grown with different levels of soil nitrogen. J. Amer. Soc. Hort. Sci. 102:533-535.

Kratky, B.A. and H. Y. Mishima. 1981. Lettuce seeding and yield response to pre-plant and foliar fertilization during transplant production, J. Amer. Soc. Hort. sci. 106:3-7.

Lorenz, O. A. and D. N. Maynard. 1988. Knott's handbook for vegetable growers, Wiley, New York,

Masson, J., N. Tremblay, and A. Gosselin. 1991. Effects of nitrogen fertilization and HPS supplementary lighting on vegetable transplants production. 1. Transplant growth. J. Amer. Soc. Hort. Sci. 116:594-598.

Me/ton, R.R. andR.J. Dufau/t. 1991. Tomato seedling growth, earliness, yield, and quality following pretransplant nutritional conditioning and lowtemperatures. J. Amer. Soc. Hort. Sci. 116:421-425.

Tremblay, N., S. Yelle, and A. Gosselin. 1987. Effects of $\mathrm{C}_{2}$ enrichment, nitrogen and phosphorus fertilization on growth and yield of celery transplants, HortScience 22:875-876.

Weston, L.A. andB,H, Zandstra. 1989. Transplant age and $\mathrm{N}$ and $\mathrm{P}$ nutrition effects on growth and yield of tomatoes, HortScience 24:88-90. 